Ralph Zenger

\title{
Die Insolvenzanfechtung aus zivilrechtlicher Perspektive
}

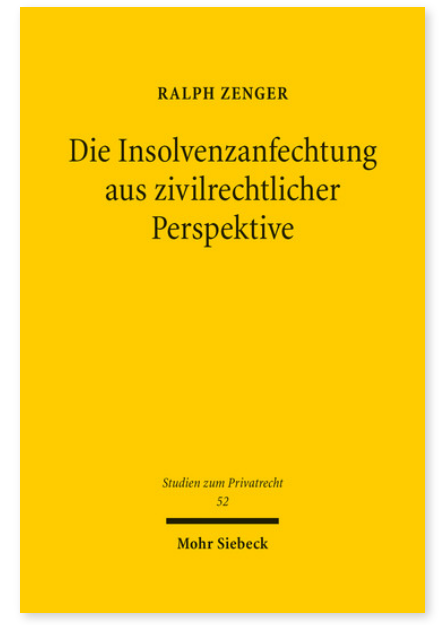

2016. XIX, 292 Seiten. StudPriv 52

ISBN 978-3-16-154677-8

DOI 10.1628/978-3-16-154677-8

eBook PDF 109,00€

ISBN 978-3-16-154676-1

Leinen $109,00 €$
Die Rechtsnatur der Insolvenzanfechtung und die sich daraus ergebenden Rechtsfolgen sind seit jeher umstritten. In Abkehr zu den üblichen Deutungsversuchen führt Ralph Zenger die Insolvenzanfechtung auf zivilrechtliche Prinzipien zurück, indem er vielfältige Vergleiche mit bekannten zivilrechtlichen Rechtsinstituten anstellt und dabei erstaunliche Parallelen offenlegt. Durch eine Rückbesinnung auf das allgemeine Zivilrecht entwickelt er eine stringente und nachvollziehbare Dogmatik der Insolvenzanfechtung. Zugleich zeigt Ralph Zenger, dass eine Anbindung an das Zivilrecht interessengerechte und rechtssichere Lösungen anfechtungsrechtlicher Problemkreise ermöglicht, insbesondere in den praktisch relevanten sogenannten Kollisionsfällen, in denen das Anfechtungsrecht des Insolvenzverwalters mit Rechten von Gläubigern des Anfechtungsgegners zu konkurrieren hat.

Ralph Zenger Geboren 1986; Studium der Rechtswissenschaft an der Friedrich-Alexander-Universität Erlangen-Nürnberg; wissenschaftlicher Mitarbeiter am Lehrstuhl für Bürgerliches Recht, Zivilprozessrecht, Insolvenzrecht und Freiwillige Gerichtsbarkeit der Universität Erlangen-Nürnberg; derzeit Rechtsreferendar im Oberlandesgerichtsbezirk Bamberg.
Jetzt bestellen:

https://mohrsiebeck.com/buch/die-insolvenzanfechtung-aus-zivilrechtlicher-perspektive-9783161546778?no_cache=1 order@mohrsiebeck.com

Telefon: +49 (0)7071-923-17

Telefax: $+49(0) 7071-51104$ 